\title{
KONTRIBUSI KECEPATAN DAN KELENTUKAN TERHADAP HASIL MENGGIRING BOLA
}

(Studi Pada Ekstrakurikuler Sepakbola Di SMK Pemuda Papar)

\author{
Budiman Agung Pratama \\ Penjaskesrek Universitas Nusantara PGRI Kediri \\ agung10@unpkediri.ac.id
}

\begin{abstract}
Abstrak
Tujuan Penelitian adalah mendapatkan data yang empiris tentang kontribusi kecepatan dan kelentukan terhadap hasil menggiring bola di SMK Pemuda Papar. Sasaran dalam penelitian ini adalah siswa Putra ekstrakurikuler sepakbola SMK Pemuda Papar. jumlah sampel yang digunakan dalam penelitian ini sebanyak 30 siswa.

Dalam pengolahan data didapatkan hasil penelitian bahwa terdapat kontribusi yang signifikan antara kecepatan terhadap hasil menggiring bola dalam permainan sepakbola, dengan hasil perhitungan data statistik r-hitung : - 0.86 pada taraf signifikan $5 \%$. Terdapat kontribusi yang signifikan antara kelentukan terhadap hasil menggiring bola dalam permainan sepakbola, dengan hasil perhitungan data statistik $r$-hitung : - 0.38 pada taraf signifikan 5\%. Terdapat kontribusi yang signifikan antara kecepatan dan kelentukan terhadap hasil menggiring bola dalam permainan sepakbola, dengan hasil perhitungan data statistik r-hitung : 0.985 pada taraf signifikan $5 \%$.

Dengan melihat analisa hasil dalam penelitian maka dapat ditarik kesimpulan bahwa ada kontribusi antara kecepatan dan kelentukan terhadap hasil menggiring bola dalam permainan sepakbola. Maka pemain atau atlet sepakbola, agar bisa mencapai prestasi yang maksimal maka harus memperhatikan kecepatan dan kelentukan.
\end{abstract}

Kata Kunci: Kontribusi, kecepatan, kelentukan, menggiring bola, sepakbola

\section{PENDAHULUAN}

Olahraga sepakbola telah menjadi salah satu cabang olahraga yang populer di Indonesia. Perkembangan olahraga sepakbola sangat membanggakan baik segi penggemar, atlet, serta kegiatan pertandingan maupun pembinaan organisasinya. Namun demikian upaya pembinaan perlu terus menerus ditumbuh kembangkan sehingga peningkatan dan pencapaian prestasi olahraga sepakbola baik tingkat nasional maupun internasional dapat lebih maju dan lebih membanggakan lagi. Hal ini tak lepas dari peran media, terutama media televisi yang tidak pernah lepas menayangkan berita-berita 
tentang kegiatan sepakbola di tanah air. Untuk itu guna meningkatkan kualitas penguasaan permainan sepakbola diperlukan adanya pembinaan yang mengarah pada prestasi bagi atlet sejak dini disertai pola-pola dan metodemetode pelatihan yang berkualitas, sehingga dapat mengangkat prestasi sepakbola di tingkat Internasional. Permainan sepakbola adalah merupakan suatu bentuk permainan yang dilakukan oleh dua kelompok pemain dan tiaptiap kelompok terdiri dari sebelas orang serta menggunakan bola sepak dan kaki sebagai alat penendangnya (Rifai, 1993 : 1). Oleh sebab itu masingmasing regu/kelompok disebut kesebelasan, dengan pembagian sebagai berikut : seorang penjaga gawang, dua orang pemain belakang (back kanan dan kiri), tiga orang pemain tengah (gelandang kanan, tengah, kiri), lima orang pemain depan (kanan dan kiri luar), (kanan dan kiri dalam), dan (seorang penyerang tengah). Untuk menjadi pemain sepakbola diperlukan kondisi fisik yang optimal supaya dapat bermain sepakbola dengan baik dan benar.Kondisi fisik adalah salah satu prasyarat yang sangat diperlukan dalam setiap usaha peningkatan prestasi seorang atlit, bahkan dapat dikatakan dasar landasan titik tolak suatu awalan olahraga prestasi. Dari pendapat di atas kita dapat menyimpulkan bahwa untuk mencapai prestasi yang tinggi dalam sepakbola seorang pemain dituntut dalam persiapan teknik dan kondisi fisik.

Kondisi fisik adalah satu kesatuan utuh dari komponen-komponen yang tidak bisa dipisahkan, baik peningkatannya, maupun pemeliharaannya (Sajoto, 1988 : 8). Artinya bahwa setiap usaha peningkatan kondisi fisik, maka harus mengembangkan semua komponen tersebut. Walaupun perlu dilakukan dengan sistem preoritas, (Komponen apa yang perlu mendapat porsi latihan lebih besar dibanding komponen lain). Sesuai status yang diketahui, setelah komponen tersebut diukur dan dinilai. Dalam bermain sepakbola, pemain dituntut untuk selalu bergerak. Gerak yang dilakukan menggiring bola, untuk melakukan gerakan tersebut diperlukan kondisi fisik tinggi. Latihan fisik pemain sepakbola dari kondisi fisik yaitu :

1. Latihan daya ledak

2. Latihan kekuatan

3. Latihan kecepatan

4. Latihan daya tahan

5. Latihan kelentukan (Muhajir, 2006 : 106). 
Dalam teknik sepakbola terdapat teknik menggiring bola, dalam menggiring bola tentunya memerlukan fisik yang dominan diantara 5 kondisi fisik diatas. Saat menggiring bola tentunya pemain memerlukan kecepatn dan kelentukan untuk mengubah arah dalam usahanya melabui lawan. Berdasarkan alasan tersebut nampaknya menarik untuk dikaji tentang kontribusi antara kecepatan dan kelentukan terhadap hasil menggiring bola dalam permainan sepakbola.

\section{METODE PENELITIAN}

Jenis penelitian ini adalah non eksperimen. Penelitian non eksperimen adalah "suatu penelitian dimana penelitian tidak memberikan perlakuan atau melakukan manipulasi terhadap variabel yang mungkin berperan dalam munculnya suatu gejala yang diamati telah terjadi”. (Maksum, 2008: 11). Desain penelitian ini adalah korelasional yaitu dengan menghubungkan antara variabel bebas dan variabel terikat. Sampel dalam penelitian ini berjumlah 30 siswa yang mengikutu ekstrakurikuler. Untuk menentukan adanya hubungan antara keduanya dan besarnya koefisisen korelasinya dalam menggumpulkan data menggunkan alat ukut berupa tes lari sprint $30 \mathrm{~m}$ (Nurhasan, 2001 : 136), tes sit and reach test.( Sajoto, M. 1988. : 75) dan menggiring bola dengan tes melakukan giringan bola dengan rintangan (Nurhasan. 2001 : 160). Untuk analisa data menggunakan rumus korelasi

\section{HASIL PENELITIAN}

Tabel 1. Mencari harga rata-rata kecepatan $\left(X_{1}\right)$, kelentukan $\left(X_{2}\right)$, dan hasil menggiring bola $(\mathrm{Y})$. Mean $\mathrm{X}_{1}, \mathrm{X}_{2}$ dan $\mathrm{Y}$

\begin{tabular}{ccc}
\hline No & Mean & Hasil \\
A & $\mathrm{X}_{1}$ & 6.24 \\
$\mathrm{~B}$ & $\mathrm{X}_{2}$ & 15.2 \\
C & $\mathrm{Y}$ & 14.98 \\
\hline
\end{tabular}

Tabel 2. Mencari korelasi antara kecepatan $\left(X_{1}\right)$, kelentukan $\left(X_{2}\right)$, dan hasil menggiring bola $(\mathrm{Y})$. Korelasi $\mathrm{X}_{1}, \mathrm{X}_{2}$ dan $\mathrm{Y}$

\begin{tabular}{cc}
\hline Korelasi & Hasil \\
$\mathrm{X}_{1} . \mathrm{Y}$ & -0.86 \\
$\mathrm{X}_{2} . \mathrm{Y}$ & -0.38 \\
$\mathrm{X}_{1} . \mathrm{X}_{2} . \mathrm{Y}$ & \pm 0.36 \\
\hline
\end{tabular}


Tabel 3. Untuk menentukan apakah harga Ry ${ }_{(1,2)}$ tersebut signifikan atau tidak harus melakukan analisis regresi. Dari analisa tersbut akan diperoleh nilai $F$ garis regresi Analisis Regresi

$\begin{array}{cc}\text { Analisis Regresi } & \text { Hasil } \\ \mathrm{SS}_{\text {reg }} & 21.404736 \\ \mathrm{MS}_{\text {reg }} & 10.702368 \\ \mathrm{SS}_{\text {res }} & 143.755264 \\ \mathrm{Df}_{\text {res }} & 27 \\ \mathrm{MS}_{\text {res }} & 5.32426904 \\ \text { Jadi }_{\text {reg }} & 2.01011029\end{array}$

Tingkat kebebasan (dk) untuk menguji adalah lawan $\mathrm{N}-\mathrm{m}=1$ atau 2 lawan 27 diperoleh $\mathrm{Fe} 5 \%=0.361$ jadi sebesar 2.01011029 itu signifikan sehingga dapat disimpulkan bahwa korelasi antar $\mathrm{Y}$ dengan $\mathrm{X} 1$ dan $\mathrm{X} 2$. Keseluruhan proses untuk memeperoleh $\mathrm{F}$ dapat dilihat dalam tabel rangkuman analisis regresi sebagai berikut :

\section{Tabel 4. Rangkuman analisis Regresi}

\begin{tabular}{lccc}
\hline Sumber Variasi & Df & SS & MS \\
Regresi (reg) & $M$ & $R^{2}\left(\sum \mathrm{Y}^{2}\right)$ & $\mathrm{R}^{2} \mathrm{~m}$ \\
& & & $\frac{(1-\mathrm{R})^{2}\left(\sum \mathrm{Y}^{2}\right)}{\mathrm{N}-\mathrm{m}-1}$ \\
Residu (res) & $\mathrm{N}-\mathrm{m}-1$ & $(1-\mathrm{R})^{2}\left(\sum \mathrm{Y}^{2}\right)$ & \\
Total & $\mathrm{N}-1$ & $\sum \mathrm{Y}^{2}$ & \\
& & & \\
\hline
\end{tabular}

\section{PENGUJIAN HIPOTESIS PENELITIAN}

Pengujiaan hipotesis pertama

Yaitu Kontribusi kecepatan terhadap hasil menggiring bola, untuk kepentingan hipotesis nihil (Ho) yang berbunyi : Tidak ada kontribusi kecepatan trerhadap hasil menggiring bola. Untuk pengujian ini dilakukan pengetesan signifikan $\mathrm{rx}_{1} \mathrm{y}$ dalam taraf signifikan 5\% seperti Nampak pada tabel dibawah ini : 
Tabel 5 Hasil Perhitungan Hipotesis Pertama

\begin{tabular}{llll}
\hline $\mathrm{Db}$ & $\mathrm{r}-$ hitung & $\mathrm{t}-$ tabel $5 \%$ & Keterangan \\
27 & -0.86 & \pm 0.361 & Signifikan \\
\hline
\end{tabular}

Pengujian Hipotesis Kedua

Yaitu kontribusi kelentukan terhadap hasil menggiring bola, untuk kepentingan hipotesis diubah nihil ( $\mathrm{Ho}$ ) yang berbunyi : Tidak ada kontribusi antara kelentukan terhadap hasil menggiring bola. Untuk pengujian ini dilakukan pengetesan signifikan $\mathrm{rx}_{2} \mathrm{y}$ dalam taraf signifikan $5 \%$ seperti tampak pada tabel dibawah ini :

Tabel 6. Hasil Perhitungan Hipotesis Kedua

\begin{tabular}{llll}
\hline $\mathrm{Db}$ & $\mathrm{r}$ - hitung & $\mathrm{t}-$ tabel $5 \%$ & Keterngan \\
27 & -0.38 & \pm 0.361 & signifikan \\
\hline
\end{tabular}

Pengujian Hipotesis Ketiga

kontribusi kecepatan dan kelentukan terhadap hasil menggiring bola, untuk kepentingan hipotesis diubah kedalam hipotesis nihil $(\mathrm{Ho})$ yang berbunyi : Tidak ada kontribusi antara kecepatan dan kelentukan terhadap hasil menggiring bola. Dan ( $\mathrm{Ha})$ : Ada kontribusi antara kecepatan dan kelentukan terhadap hasil menggiring bola. Untuk pengujian ini dilakukan pengetesan signifikan $\operatorname{Ry}(1,2)$ dalam taraf signifikan $5 \%$ seperti tabel dibawah ini :

Tabel 7. Hasil Perhitungan Hipotesis Ketiga

\begin{tabular}{lll}
\hline $\mathrm{Db}$ & $\mathrm{r}-$ hitung & $\mathrm{t}-$ tabel \\
$5 \%$ & Signifikan/ Non Signifikan
\end{tabular}
27
0.985
$\pm 0,361$
Signifikan

Berdasarkan tabel hasil perhitungan $r$ hitung $R y(12)$ lebih besar dari pada $r$ tabel berarti nilainya signifikan.

\section{DISKUSI}

\section{Kontribusi kecepatan terhadap hasil menggiring bola}

Dari hasil pengujian hipotesis, diperoleh hasil perhitungan $r$ hitung $r x_{1} y$ lebih besar dari $r$ table, berarti nilainya signifikan dan Ha diterima. Faktor-faktor yang memepengaruhi kecepatan seseorang menurut (Fox dan Foss 1988) tenaga 
otot, viscositas otot, kecepatan reaksi, kecepatan kontraksi, koordinasi antara syaraf pusat dan otot, ciri antropometrik, dan daya tahan, kecepatan. Berorientasi pada pengertian tentang kecepatan dan penerapannya dalam aktivitas olahraga, unsur kecepatan merupakan salah satu unsur yang penting dalam mencapai hasil optimal. Implikasi kecepatan berupa kecepatan reaksi sebagian, sedangkan kecepatan gerak adalah kecepatan gerak anggota tubuh secara keseluruhan dalam menempuh jarak tertentu seperti lari.

\section{Kontribusi kelentukan terhadap hasil menggiring}

Dari hasil pengujian hipotesis, diperoleh hasil perhitungan $r$ hitung $r x_{2} y$ lebih besar dari $r$ table, berarti nilainya signifikan dan Ha diterima. Flexibilitas sering dianggap sebagai suatu faktor tunggal dalam ketrampilan (Sucipto 2000). Hasil penelitian menunjukkan bahwa ternyata, terdapat 13 faktor perbedaan flexibilitas. Jadi flexibilitas bukan faktor tunggal dalam ketrampilan pada umumnya. Kesimpulan bahwa, faktor flexibilitas sangat penting, dan harus disesuaikan dengan kepentingan cabang masing-masing, flexibilitas pesenam, berbeda dengan flexibilitas pemain bola. Jadi flexibilitas pada prinsipnya tidak dapat digeneralasikan.

\section{Kontribusi kecepatan dan kelentukan terhadap hasil menggiring bola}

Dari hasil pengujian hipotesis, diperoleh hasil perhitungan $r$ hitung $R_{(1,2)}$ lebih besar dari $r$ table, berarti nilainya signifikan dan Ha diterima. Untuk menggiring bola dengan baik seorang pemain harus mempunyai dasar-dasar menggiring bola dengan baik. Seorang pemain sering berlatih dengan benar sejak usia dini. Karena teknik dan kondisi fisik yang baik akan menghasilkan giringan secara baik dan benar (Munawar, $2006:$ 7)

\section{KESIMPULAN}

Dengan melihat analisa hasil dalam penelitian maka dapat ditarik simpulan bahwa ada kontribusi antara kecepatan dan kelentukan terhadap hasil menggiring bola dalam permainan sepakbola. Maka pemain atau atlet sepakbola, agar bisa mencapai prestasi yang maksimal maka harus memperhatikan kecepatan dan kelentukan.

\section{DAFTAR PUSTAKA}

Fox, E.L., Bower, dan Foss. 1988. The Physiological Basic of Physical Education and Athletics, Fourth Edition. New York: Saunders College Publishing 
Maksum A. 2008. Metodologi Penelitian. Surabaya: University Perss

Muhajir. 2006. Pendidikan jasmani olahraga \& kesehatan, Jakarta: Pionir Jaya

Munawar. 2006. Buku pendidikan jasmani, olahraga, dan kesehatan. Yogyakarta: Andi

Nurhasan. 2001. Tes dan Pengukuran Pengantar, Kegunaan Tes dan Pengukuran Kriteria Tes. Jakarta: kurnia.

Rifai, S. 1993. Buku jurnal sepakbola. . Jakarta: Rineka Cipta.

Sajoto, M. 1988. Pembinaan kondisi fisik dalam olah raga. FPOK-IKIP Semarang.

Sucipto dkk, 2000. Sepak Bola. Departemen Pendidikan Nasional Direktorat Jenderal Pendidikan Dasar dan Menengah, Proyek Penataran Guru SLTP Setara D-III. 